\title{
LAS RACIONALIDADES NAHUA Y DE LA MODERNIDAD
}

\author{
José de Jesús Godínez Terrones* \\ doi: 10.11144/Javeriana.uph38-76.rndm
}

\begin{abstract}
RESUMEN
Cuando llegaron los conquistadores al valle de México se asombraron de las creaciones de la cultura heredera de la tradición tolteca. En busca del reconocimiento de esta cultura, en este artículo se examina que palabras como verdad, pensar y dudar tienen una connotación muy diferente en la filosofía moderna europea, a la cultura del Anáhuac, que floreció en el Valle de México entre los siglos IX y xvi. Se presenta así una comparación del proceso para obtener el conocimiento verdadero en la racionalidad del mundo nahua del siglo Xvi y en tres autores de la modernidad europea: Descartes, Kant y Hegel. Se encuentra que la modernidad presenta un sujeto dominante que fundamenta un pensamiento autorreferencial, mientras que en la cultura nahua el ideal es el hombre de "corazón de piedra y rostro sabio" que busca lo verdadero, "lo que tiene raíz", y lo expresa a través de la poesía, "la flor y el canto".

Palabras clave: filosofía nahua; modernidad; racionalidad; verdad; tolteca
\end{abstract}

Universidad Franciscana de México, León, Guanajuato, México.

Correo electrónico: jjoseph94@hotmail.com

Para citar este artículo: Godínez Terrones, J. J. (2021). Las racionalidades nahua y de la modernidad. Universitas Philosophica, 38(76), 139-169. ISSN 0120-5323, ISSN en línea 2346-2426. doi: 10.11144/Javeriana.uph38-76.rndm 


\title{
NAHUA AND MODERN RATIONALITIES
}

\begin{abstract}
When the conquerors arrived in the Valley of Mexico, they were amazed at the creations of the culture inherited from the Toltec tradition. With the prurpose of acknowledging this culture, this paper points out that words such as truth, thinking, and doubt have a very different connotation in modern European philosophy, to the Anahuac culture, which flourished in the Valley of Mexico between the $9^{\text {th }}$ and $16^{\text {th }}$ centuries. This writing presents a comparison of the process to obtain true knowledge according to the rationality of the Nahua world of the $16^{\text {th }}$ century and three authors of European modernity: Descartes, Kant and Hegel. Modernity is found to present a dominant and egocentric subject with self-referential thinking. In the Nahua culture the ideal is the man with a "heart of stone" and a "wise face" who seeks what is true, what has roots, and expresses it through poetry, "the flower and the song".
\end{abstract}

Keywords: Nahua philosophy; modernity; rationality; truth; Toltec 


\section{Introducción}

La América precolonial ha sido terreno de grandes civilizaciones cuyo legado cultural ha llegado parcialmente hasta nosotros. Si bien la grandeza de estas culturas centenarias fue truncada por la llegada de conquistadores europeos a Mesoamérica, algunos códices han sobrevivido al tiempo y ahínco de los dominadores por destruirlos. Los pocos que han perdurado permiten atisbar la riqueza de la cultura y su estudio ha permitido tener una nueva visión de la vida de los pueblos originarios.

En este escrito se presenta una comparación entre el proceso para obtener el conocimiento verdadero en la racionalidad del mundo nahua del siglo xvi y el mismo proceso en tres autores de la modernidad europea: Descartes, Kant y Hegel. Se muestra que en el Valle de México floreció una civilización con una estructura conceptual amplia y profunda que cohesionaba la visión del mundo y su sentido, y con base en ello se señala que es necesario un cambio epistemológico que permita una comprensión de la realidad más rica y menos fragmentada de lo que la modernidad ha ofrecido.

Las fuentes aquí utilizadas sobre la cultura nahua son trabajos presentados por estudiosos de esta cultura a partir de la información dispersa en códices u obras de españoles que tuvieron contacto con esta cultura, y es importante señalar que un estudio paleográfico de dichos códices rebasa con mucho la presente investigación. Además, es preciso anotar que el legado cultural nahua nos ha llegado a través de diferentes investigaciones con intereses y estructuras conceptuales diversas, y que no ha sido el producto del trabajo de un solo individuo. En cuanto a los filósofos europeos, pródigamente conocidos en ámbitos académicos actuales, en este caso no precisan de mucha hondura en su estudio sino que se rescatan elementos indispensables que permitan la comparación con los aspectos estudiados de la cultura nahua. Las consecuencias e implicaciones del pensamiento en estos autores han sido objeto de amplias y profundas investigaciones de muchos académicos contemporáneos y no serán abordadas en este artículo. El término racionalidad se ha entendido "como una categoría que permite identificar cómo los hombres reconocen y llevan a cabo sus fines" (Giraldo Garcés, 2007, p. 54); o también como proceso, como actuación, ejercicio o realización de la razón para obtener conocimiento (De-Regil \& Casanueva, 2008, p. 524). 
Cuando los conguistadores llegaron a Tenochtitlán, la capital del imperio azteca, fundada por los mexicas en el año 2 Casa o 1325 d. C., según el Códice Mendoza (Rubio Fernández, 2008, p. 55), se quedaron asombrados de la belleza de la ciudad: "decían que si aquello que veían era cosa de sueño" (Sejourné, 1984, p. 11). Edificada sobre una laguna y conectada por tres amplias calzadas, la habitaban trescientas mil personas y recibía sesenta mil visitantes diarios que comerciaban oro, plata, plumas de ricos colores, piedras preciosas, frutas de zonas tropicales y una numerosa cantidad de mercancías. Era una ciudad tan maravillosa que los soldados no encontraron palabras para explicar su grandeza, contentándose con apuntar que no había tal magnificencia ni en España, con torres tan altas que "la más principal es más alta que la torre de la iglesia mayor de Sevilla. Son tan bien labradas, así de cantería como de madera, que no pueden ser mejor hechas ni labradas en ninguna parte" (Cortés, 1985, p. 64).

Vista por primera vez por los conquistadores en 1519, la magnífica ciudad de Tenochtitlán surgió cuando llegaron los aztecas como refugiados en 1325 a establecerse, cumpliendo la profecía de "la famosa águila, sobre el tunal, sobre la piedra, comiéndose a la serpiente" (Bernal, 1984, p. 128). La construcción de un pequeño oratorio fue el punto de partida de la gran ciudad construida por el pueblo del sol, que allí manifestaba su integración cultural y su espíritu guerrero.

Con Tlacaélel como consejero del rey, "nace la visión místico-guerrera del pueblo azteca, que se considera a sí mismo como el pueblo elegido del sol" (León-Portilla, 1983, p. 89). Todas las conquistas y guerras estaban justificadas por esta idea del pueblo del sol: proporcionar la sangre de los sacrificios humanos para alimentar al sol (Mikulska Dabrowska, 2007, pp. 13-14). El sacrificio humano formaba parte de un sistema de creencias y rituales, y se realizaba con el propósito de mantener la vitalidad del universo (Ocaña-Servín et al., 2016). La humanidad contribuye a la continuación y renovación del cosmos mediante "la flor y el canto" (in xóchit in cuicatl), y con ritos que incluyen "el autosacrificio y el sacrificio de plantas, animales y seres humanos" (Maffie, 2008, p. 40). La relación del ser humano con el universo es de participación y de reciprocidad para mantener la existencia de ambos. "El hombre ha sido creado por el sacrificio de los dioses y debe corresponder ofreciéndoles como alimento la sustancia mágica, la 
vida que reside en la sangre y corazón humanos" (Barrera-Ramírez \& GuerreroOrduna, 1999, p. 650).

El sacrificio humano es un acto religioso en el que se consagra a la persona por una oblación. La palabra sacrificio deriva de los vocablos latinos sacer y facere, hacer sagrado, y por el sacrificio se pasa del plano ordinario a un plano sagrado (Baena, 2018, p. 68). "Es un acto religioso que, por la consagración de una víctima, modifica el estado de la persona moral que lo consuma o de algunos objetos en los que la persona se interesa" (Mauss \& Hubert, 2010, p. 83). El sacrificio implica necesariamente una oblación, la ofrenda o una parte de la ofrenda es destruida (Mauss \& Hubert, 2010, p. 81).

Este misticismo guerrero del pueblo del sol (Jansen, 1997, p. 78) llevó a los aztecas a conquistar tierras de un océano a otro, hasta Chiapas y Guatemala. Tlacaélel reescribió la historia del pueblo azteca y reinterpretó a su modo la antigua doctrina tolteca para incorporarla a su visión místico-guerrera.

Sin embargo, los señoríos del Valle de México, herederos de la tradición cultural nahua, "parecían repudiar el misticismo guerrero impuesto por Tlacaélel” (León-Portilla, 1983, p. 114). Mantenían una postura diferente al militarismo azteca, siguiendo la tradición que venía de los que fueron los anteriores pobladores de esta tierra de México: los toltecas. "Se nos dice que por su extrema habilidad artística fueron llamados toltecas, término que, en náhuatl, significa maestros artesanos" (Sejourné, 1984, p. 29). El ideal del hombre sabio era referido siempre a la toltequidad.

\section{Los difrasismos}

LA LENGUA NÁHUATL HACE USO FRECUENTE DEL DIFRASISMO, "un procedimiento que consiste en expresar una misma idea por medio de dos vocablos que se completan en el sentido, ya por ser sinónimos, ya por ser adyacentes" (Garibay, 1961, p. 115). Un ejemplo de difrasismo lo relata Sahagún cuando la partera lava al niño: “Toma el agua, recíbela. Aquí está para que crezcas, para que brotes" (Xicmocuili, xicmocelili, izcatqui inic titzmoliniz, inic ticeliaz). El difrasismo consiste en inic titzmoliniz, inic ticeliaz, 'para que crezcas, para que brotes' (López Austin, 2003, p. 153). Otro difrasismo para referirse a los conocimientos transmitidos es la frase: tlilli tlapalli, compuesta por la yuxtaposición 
de las palabras tlilli ('la tinta negra'), y tlapalli ('la pintura de colores'), que tiene el sentido metafórico de escritura pintada, significando conocimiento, sabiduría y tradición (Wright Carr, 2011, p. 286). El difrasismo se presenta también en forma de paralelismo: por ejemplo, Choquiztli moteca, ixayotl pixabui se traduce como 'el llanto se difunde, las lágrimas gotean'. Igualmente, los difrasismos son usados como metáforas que denotan una realidad que no se nombra directamente con las palabras, como ejemplo: In iomiyo in inacayo, que literalmente se traduce como 'su osamenta, su carnación' y que significa 'la persona constituida de huesos y carne'; también, cuando se dan muestras de humildad se dice Itolol imalcoch, que de manera literal traduce 'su inclinación de cabeza, su doblegamiento'; o Cententli cencamatl, un labio, una boca', que significa 'decir unas cuantas palabras' (Máynez, 2009, pp. 237-244).

Un difrasismo para referirse a la persona es in ixtli, in yóllotl: 'cara, corazón'. "Ixtli, 'cara', apunta al aspecto constitutivo del yo, del que es símbolo el rostro. Yóllotl, 'corazón', implica el dinamismo del ser humano que busca y anhela" (León-Portilla, 2006, p. 384). “In ixtli, in yóllotl, 'la cara, el corazón', simbolizan siempre lo que hoy llamaríamos fisonomía moral y principio dinámico de un ser humano" (León-Portilla, 1980, p. 192). Así, conseguir la madurez es "buscar lo conveniente, lo recto, porque solo así se logrará poseer un 'rostro y un corazón verdadero"' (León-Portilla, 2006, p. 242). Cuando se dice "daré pena a vuestros rostros, a vuestros corazones" o "hago reverencia a vuestros rostros, a vuestros corazones", se hace referencia a la persona de los interlocutores (León-Portilla, 2006, p. 190).

Hay dos formas del lenguaje en los nahuas: el macehualtolli y el tecpillatolli. El primero es el lenguaje coloquial, una forma de habla cotidiana, y el segundo una forma de hablar cuidadosa de los poetas y sabios (Molina, 1571, p. 93). Los difrasismos no eran para uso diario (Mikulska Dąbrowska, 2010, p. 338). $\mathrm{Su}$ uso mantiene una estructura específica de acuerdo a los actores sociales en rituales y aspectos institucionales de la comunidad (Montes de Oca, 2000, p. 368). En ese sentido, los difrasismos son metáforas para exaltar en ocasiones las características de una persona o linaje noble. Dos ejemplos de este modo de referirse a las cualidades de una persona son: in maquiztli in tlaçotli, 'pulsera, objeto precioso', e in teoxihuitl in quetzalli, 'turquesa, pluma fina' (Montes de Oca, 2016, pp. 252-259). La traducción de los difrasismos plantea la cuestión 
de que "aquello que se concibe como una unidad en la lengua-origen no lo es necesariamente en la lengua-destino" (Montes De Oca, 1997, p. 33). Al partir del dominio de origen, es decir, del contexto natural en la sociedad nahua, y llegar a la lengua destino, el español, no siempre resulta clara la unidad de referencia. Ello es evidente en que para referirse al ser humano se dice in maitl in icxitl, que literalmente es 'mano pie' (Mikulska Dąbrowska, 2010, p. 333), una asociación que no resulta natural en la lengua de destino.

\section{La toltequidad}

EN SUS ORÍGENES TOLLAN significaba 'en el lugar de espadañas' o 'tule', que son sitios donde abundan agua y vegetación, y posteriormente llegó a significar la idea de población grande y floreciente, ciudad y metrópoli (León-Portilla, 1980, p. 18; Florescano, 1963, p. 195). En ese sentido, Tollan se volvió un concepto referencial no ya de una ciudad o lugar, sino más bien de un nivel de cultura, sabiduría y refinamiento, de un logro alcanzado dentro de los marcos culturales, ciencia, medicina y arte. Toltécatl se deriva de Tollan, y significa 'el que habita en un Tula'. Los toltecas "eran buenos hombres y allegados a la virtud" (Sahagún, 1999, p. 597). Eran sabios, "los conocedores de las cosas ocultas, los poseedores de la tradición, los fundadores de pueblos y señoríos" (León-Portilla, 1980, p. 26).

Toltécatl es quien ha conseguido la perfección en un arte, un preservador de la antigua cultura heredada. Toltecáyotl, que significa 'toltequidad' (Sodi, 1962), es un término abstracto y designa "el conjunto de todo aquello que pertenece y es característico de quienes viven en una Tollan, una ciudad” (León-Portilla, 1980, p. 18). Toltecatl significa artista y también designa al grupo náhuatl; y cuando se le añade la terminación -yotl forma el término abstracto. La toltecáyotl es, pues, la herencia de los logros de los toltecas en cuanto a instituciones, ciencia, arte, urbanismo, educación, y por ello representa la excelencia de la cultura tolteca.

Tollan Teotihuacan es para los mexicas el modelo de una toltecáyotl. Es la tollan en donde se ha dado el refinamiento y la sabiduría. "Los toltecas eran muy ricos, eran felices, nunca tienen (sic) pobreza ni tristeza. Los toltecas eran experimentados, acostumbraban dialogar con su propio corazón. Conocían experimentalmente las estrellas, les dieron sus nombres. Conocían sus influjos, sabían bien cómo marcha el cielo" (León-Portilla, 1980, p. 29). Los mexicas se sentían 
herederos de la toltequidad, que les dio un rostro y un corazón. Por ello, es una tradición que preservaban y cultivaban en "los centros de educación: los calmécac y telpochcalli, en los templos, en el hogar y, por todos los medios al alcance, buscaban hacer suyo aquello que tenían como recto y bueno y que a la vez era menester acrecentar" (León-Portilla, 1980, p. 32).

Los tlamatinime ejercían el arte de criar y educar a los hombres, llamado tlacahuapabualiztli (Hernández Díaz, 2013, p. 41), en el calmécac y telpochcalli, centros de educación pública, donde forjaban la identidad cultural. La asistencia a estos centros era obligatoria, pues allí se transmitía la toltecáyotl. Un tlamatini es un sabio náhuatl que en su función de maestro "hace sabios los rostros ajenos, hace a los otros tomar una cara, una personalidad, los hace desarrollarla. Les abre los oídos, los ilumina. Es maestro de guías, les da su camino, de él uno depende" (León-Portilla, 1983, p. 123). El ideal de la educación nahua era forjar: "El hombre maduro: corazón firme como la piedra, corazón resistente como el tronco de un árbol; rostro sabio. Dueño de un rostro y un corazón, hábil y comprensivo" (León-Portilla, 1983, p. 147).

La misión del sabio es enseñar a los hombres a desarrollar su personalidad, la reflexividad, el autoconocimiento, "para que conociéndose se hagan cuerdos y cuidadosos" (León-Portilla, 2006, p. 81). El sabio es un "teixcuitiani: 'que-a-losotros-una-cara-hace-tomar”" (León-Portilla, 2006, p. 388). El sabio que transmite la sabiduría, como un proceso de crecimiento individual y como una herencia de la toltequidad, es un teixtlamachtian: 'que a los rostros de los otros comunica la sabiduría sabida'. Es un "teixtomani: 'que-desarrolla-los-rostros-ajenos" (León-Portilla, 2006, p. 389), para que se vuelvan "de rostro sabio", y promueve el desarrollo del ser humano que viene al mundo falto de un rostro, de una personalidad que los tlamatinime ayudan a forjar. En cambio el hechicero, el mal sabio, destruye la personalidad en vez de desarrollarla, y es el que "a-los-otroshace-perder-su-rostro" (León-Portilla, 2006, p. 73).

Sahagún en Coloquios y Doctrina Cristiana (fol. 34v) y en el Códice Florentino (libro 10, cap. 8) habla de las funciones de los tlamatinime. El tlamatini tiene una función sacerdotal. Otra función es la de adivino, escucha confesiones, media entre los dioses y el pueblo. Una función más es la de hechicero, un guardián que cuida de la comunidad. La cuarta función es la de dueño de los libros sagrados, la cuenta de los días y cumplimiento de las profecías. León-Portilla 
traduce tlamatini como 'sabio, filósofo' en el Códice Matritense. Matini es 'el que conoce'. Mati significa 'conocer', tlateumatini es 'el sabio de las cosas piadosas', ilhuicacmatini es 'el sabio del cielo', y mictlanmatini se traduce como 'el sabio del otro mundo, el mictlan' (Graña-Behrens, 2012, pp. 23-25).

Mati significa tanto 'saber' como 'sentir'. Recordar algo es tlalnamiqui, 'encontrar las cosas con su mente' (Johansson, 2012, p. 59). El verbo náhuatl tlalnamiqui significa 'pensar, encontrar', son dos conceptos relacionados entre sí. Tla-ilnamiqui, inamiqui variante de elnamiqui, está compuesto del sustantivo elli, 'hígado o pecho', y del verbo tla-namiqui, 'encontrar'. Recordar sería entonces literalmente 'encontrar su hígado, o su pecho' ya que elli designa también más generalmente 'el pecho' (Johansson, 2004, p. 211). En este mismo sentido, Molina (1571) en su diccionario traduce el sustantivo tlalnamiquiliztli como 'pensamiento' y tlamatiliztli, como 'sabiduría' o 'embaucamiento' (p. 126). Hay, pues, un estrecho vínculo en el náhuatl entre pensar y recordar.

El tlamatini hace sabios los rostros ajenos, los pone frente a un espejo, hace que en ellos aparezca una cara. "En este sentido, enseñar a 'tomar rostro' y 'humanizar el querer' de sus educandos parece haber sido la meta buscada por los maestros en los Calmécac" (León-Portilla, 2006, p. 192). "Flor y canto" (in xóchitl in cuicatl) es la manera como los tlamatinime expresan y se aproximan a la verdad. La verdad está relacionada con cómo vivir en este mundo con una ética, no con las cuestiones metafísicas de la filosofía occidental. Los tlamatinime conciben el arte, in xóchitl in cuicatl, como poiésis estética que le da sentido a la vida, de modo que no comparten la preocupación epistemológica y metafísica de la verdad como conceptualización del mundo, que es propia de las filosofías enunciativas occidentales (Montiel, 2019).

Para ser sumo sacerdote no se atendía a la condición socioeconómica de quien lo pretendía, no importaba que no tuviera linaje o fuese pobre; en cambio, se atendía a su género de vida, a la pureza de su corazón, a su corazón firme, a que fuese sabio en las cosas de Dios. Se decía que "'tenía a Dios en su corazón' (téutl yiollo) y que era 'sabio en las cosas divinas' (in tlateumatini)" (León-Portilla, 2006, p. 230). El sumo sacerdote recibía el título de Quetzalcóatl, quien dio origen a la toltecáyotl.

El toltécatl, 'el artista', es "capaz, se adiestra, es hábil; dialoga con su corazón, encuentra las cosas con su mente. El verdadero artista todo lo saca de su corazón" 
(León-Portilla, 2006, p. 261). Ninoyolnonotza significa 'hablo y hablo con mi corazón'. Reflexionar es 'dialogar con el corazón' (León-Portilla, 2004, p. 100), y no es una introspección en el ámbito meramente cognitivo, es "fundir la argumentación intelectualmente configurada en el crisol de la sensibilidad" (Johansson, 2012, p. 62). El toltécatl es íntegro: dueño de un rostro, dueño de un corazón, es dueño de sí, de él es humanizar el querer de la gente, "la divinidad se mete en su corazón (yoltéotl) y hace de él un artista: 'un corazón en-diosador de las cosas', tlayolteuviani” (León-Portilla, 2006, p. 180). El yoltéotl, 'Dios en el corazón', 'un corazón endiosado' es el supremo ideal humano del sabio y artista nahua.

La finalidad de la educación nahua es forjar "el hombre maduro: corazón firme como la piedra, corazón resistente como el tronco de un árbol; rostro sabio. Dueño de un rostro y un corazón, hábil y comprensivo" (León-Portilla, 1983, p. 147). El tlamatini es una gruesa tea que no ahúma, da sabiduría a los rostros ajenos, enseña cómo se ha de vivir, a obedecer a las personas y respetarlas. "Cómo deben entregarse a lo conveniente, lo recto, y cómo han de evitar lo no-conveniente, lo no recto" (León-Portilla, 1980, p. 194). La acción del tlamatini está encaminada a proporcionar respuestas prácticas a las cuestiones de la existencia humana: “¿Cómo los humanos caminan en equilibrio y así prosperan sobre la tierra?” (Maffie, 2008, p. 39) ${ }^{1}$. Se busca la conveniencia y la rectitud, in quállotl in yécyotl, in quállotl proviene del verbo qua: 'comer', que con el sufijo -llotl viene a significar 'la cualidad de todo aquello que es comible', de lo que puede ser asimilado por el propio yo, o le es conveniente. Con el difrasismo in quállotl in yécyotl, 'lo conveniente, lo recto', se expresa que "lo bueno es tal por convenir al ser humano ya que puede ser apetecido y asimilado por este" (León-Portilla, 2006, p. 235). La bondad moral es buena, conveniente y apetecible.

En los centros de estudios recibían con insistencia 'la acción que da sabiduría a los rostros ajenos', ixtlamachiliztli: la educación, la prudencia y la cordura. El tlamatini "es hombre serio. Cualquiera es confortado por él, es corregido, es enseñado. Gracias a él la gente humaniza su querer y recibe una estricta enseñanza. Conforta el corazón, conforta a la gente, ayuda, remedia, a todos cura” (León-Portilla, 1983, pp. 123-124). La educación buscaba 'rostros sabios'

1 "How can humans walk in balance and so flourish upon the earth?" 
y 'corazones firmes como la piedra', ixtlamati, yollótetl. El culmen de la educación y de la perfección humana es cuando entra Dios en el corazón del hombre, Yoltéutl, formada por yólotl, 'corazón', y Téutl o Téotl, 'Dios': 'corazón endiosado' o 'Dios en su corazón (Manrique, 1960, p. 202). Se vuelve artista, “un corazón divinizador de las cosas': tlayolteuviani” (León-Portilla, 2006, p. 384).

Lee (2017) considera que Sahagún en el Códice Florentino (libro X) y Luis Vives en el Praelectio in sapientem muestran una estrecha relación entre las características de los sabios europeos y las de los nahuas (p. 296). Sahagún trató de identificar ese tipo de personas, tlamatinime, con los sabios de Roma y Grecia clásicas: "Como hizo Sahagún con su proyecto tlamatinime, León-Portilla tomó la cultura clásica europea como punto de partida indispensable para examinar y evaluar la cultura prehispánica" (p. 305)². Este es un problema frecuente cuando la cultura investigada es muy diferente a la del investigador. El investigador ve la cultura ajena con sus propias estructuras culturales y mentales, pero ¿es posible ver el mundo sin las estructuras propias? Estos cuestionamientos se pueden profundizar más en Payás (2006).

\section{El rostro y corazón nahua}

EL CORAZÓN TIENE UN SIGNIFICADO DIFERENTE al referencial semántico de la lengua de castilla. "El corazón, yóllotl, se asocia a las facultades cognoscitivas, volitivas y creativas" (León-Portilla, 2004, p. 100). Encontramos frases como acohuetzin noyollo que literalmente es 'hacia arriba va mi corazón' y se traduce como contemplar. Olvidar se dice 'no tengo corazón', aniyollo. El virtuoso es Cualli iyollo, literalmente, es 'bueno su corazón'. Cuando algo es de buena voluntad, se dice noyollocopa, 'desde mi corazón'. Yoltehuia (nitla) es 'obrar sobre las cosas con corazón endiosado' y se traduce como inventar. La meditación es una 'lectura del corazón', neyolpoaliztli (López Austin, 2004, pp. 222-228)

Ixtli inyollotl es usado para denominar a la persona, ixtli, significa 'ojo, rostro', inyollotl 'corazón' (Mikulska Dąbrowska, 2010, p. 333). El hombre de rostro sabio y corazón de piedra es un ser maduro que no da su corazón a cada cosa. El

2 "Just as Sahagún did for his tlamatinime project, León-Portilla took a clasisical European culture as the indispensable starting point for examining and evaluating Prehispanic culture." 
rostro es la manifestación de un yo que se ha ido adquiriendo y desarrollando por la educación: "el rostro connota aquello que caracteriza la naturaleza más íntima del yo peculiar de cada hombre” (León-Portilla, 2006, p. 190).

López Austin (1991) puntualiza que el ixtli, se traduce también como 'ojo' y alude un órgano de percepción por excelencia, a un órgano que realiza una función previa a la sensación y no debe traducirse como rostro. El difrasismo in ixtli, in yollotll, "se refiere a aquella parte del hombre en la que se unen la sensación, la percepción, la comprensión y el sentimiento, para integrar una conciencia plena que se encuentra en comunicación con el mundo exterior" (p. 321). López Austin, Mikulska y Portilla concuerdan en que in ixtli inyollotl significa 'persona.' El corazón es el aspecto dinamizador del rostro, es el que mueve hacia una búsqueda, es el que hace que el hombre tienda hacia algo, el corazón es una energía con tendencia a lo verdadero, "es decir aquello que confiere dinamismo al yo” (León-Portilla, 2006, p. 191).

Los nahuas le atribuían al corazón el dinamismo de la voluntad y la concentración máxima de la vida. "Yóllotl, 'corazón', etimológicamente se deriva de la misma raíz de oll-in 'movimiento', para significar en su forma abstracta de yóll-otl la idea de "la movilidad de cada quien”" (León-Portilla, 1983, p. 147), derivado también de yoli, significa, en su forma abstracta, 'vitalidad' (León-Portilla, 2006, p. 396), procede de yol, 'cosa redonda, la bola' (López Austin, 2004, p. 222). El corazón es una 'cosa redonda', es el núcleo dinámico que mantiene al ser vivo (Viesca Treviño et al., 2005, p. 230). "Yóllotl significa la esencia o fuerza de la vida, lo que es propio del ser viviente” (León-Portilla, 2004, p. 100).

El corazón es el aspecto dinamizador del rostro, mueve hacia una búsqueda, hace que el hombre tienda hacia algo, y es una energía con tendencia a lo verdadero, a lo firme, a lo que tiene raíz. Es ímpetu que lanza al hombre sobre la realidad evanescente del mundo, el "Tlaltícpac, 'lo sobre la tierra', [es decir] lo que está aquí, lo que cambia, lo que todos vemos, lo manifiesto" (León-Portilla, 2006, p. 58). El tlaltícpacyoli yoli es una realidad fugaz, perecedera, que no tiene raíz, ni fundamento en sí misma.

El esfuerzo del hombre por adquirir 'un rostro', en el tlalticpac, en la tierra, no siempre es fácil, pues en ese impulso va dando su corazón a cada cosa, sin rumbo, ahuicpa: 'lo va perdiendo. "Sobre la tierra es difícil ir en pos de algo verdaderamente valioso” (León-Portilla, 2006, p. 179). La búsqueda de lo verdaderamente 
valioso lleva al ser humano a apegos que destruyen al corazón. “¿Qué era lo que acaso tu mente hallaba? ¿Dónde andaba tu corazón? Por eso das tu corazón a cada cosa, sin rumbo lo llevas: vas destruyendo tu corazón. Sobre la tierra ėacaso puedes ir en pos de algo?" (León-Portilla, 2006, p. 57). El 'corazón', yóllotl, aquello que confiere dinamismo al yo, entre otras funciones posee la de anhelar algo (León-Portilla, 2006, p. 191).

¿Qué es lo verdaderamente valioso que anhela el hombre? El hombre es un ser necesitado, con anhelos, y trata de llenar ese vacío, es un "ladrón de cantares, corazón mío, ¿dónde los hallarás? Eres menesteroso, como de una pintura, toma bien lo negro y rojo (el saber). Y así tal vez dejes de ser un indigente" (LeónPortilla, 1983, p. 168). El ser humano es un ser deseoso de sabiduría que está plasmada en la tradición. Tlilli tlapalli, 'la tinta negra, la tinta roja', es un difrasismo para referirse a la sabiduría y tradición (Wright Carr, 2011, p. 286). Es menesteroso y tiene un corazón con ansias de plenitud. El conocimiento que encuentra en la tradición ayuda a buscar lo recto, lo conveniente. Con un rostro sabio y corazón firme es como el hombre puede estar realizando "lo conveniente, lo recto, con esto estarás en pie, serás verdadero" (León-Portilla, 2006, p. 242).

El corazón es firme cuando se realiza lo recto, lo conveniente. El corazón está dividido cuando hay duda, "ome yolloa, literalmente 'hacerse dos el corazón' o '(dividirse en) dos el corazón'” (Johansson, 2012, p. 62). Ome yolloa se traduce como 'duda'. El que piensa, el que especula se dice moyolnonotzani: 'el que dialoga con su propio corazón'. La expresión está formada por yolotl, 'corazón', notza, 'hablar', en su forma superlativa: nonotza, precedidas por el pronombre reflexivo mo: 'sé, a sí mismo', 'con su mismo' y con la terminación sustantiva ni (Manrique, 1960, p. 203). El artista, como también se traduce moyolnonotzani, dialoga con su corazón, medita en su conciencia sobre la verdad, y escudriña la perfección de su obra. Es pensativo, escudriñador de cosas arduas (Molina, 1571, p. 58).

El sabio sigue la vieja regla tlamanitiliztli, formada por $t l a$, 'cosas'; mani, 'permanecen' o 'están permanentemente'; y liztli, sufijo propio de los sustantivos abstractos. Todo el compuesto: "tlamani-ti-liztli viene a significar 'conjunto de las cosas que deben permanecer”" (León-Portilla 2006, p. 234). Se ha de buscar lo que es verdadero, lo que permanece, lo que tiene fundamento, lo que no es evanescente.

Para los nahuas, la verdad, neltiliztl, deriva "de la misma raíz que nelhuáyotl, 'cimiento, 'fundamento'” (León-Portilla, 2006, p. 386). La verdad connota la 
cualidad de estar firme, bien cimentado o enraizado. Cuando Nezahualcóyotl (1402-1472), el rey poeta de Texcoco, se pregunta: “¿Es que acaso se vive de verdad en la tierra?" y responde “ $i N o$ por siempre en la tierra, solo breve tiempo aquí! Aunque sea jade: también se quiebra; aunque sea oro, también se hiende, y aun el plumaje de quetzal se desgarra" (Martínez, 1984, p. 186), enfatiza la caducidad del mundo, aún lo considerado valioso como el jade, el oro, el plumaje del quetzal. Por ello, la búsqueda de la verdad es una pregunta por la raíz, por la fundamentación de la realidad contingente. ¿ Tiene algún cimiento la realidad o es un mero sueño?

La transitoriedad del hombre es tan notoria que parece que "solo venimos a soñar, solo venimos a dormir: no es verdad, no es verdad que venimos a vivir en la tierra" (León-Portilla, 2006, p. 203). No es en la tierra en donde está lo verdadero, lo que da cimiento, la raíz. "Por prestadas tengamos las cosas, oh amigos, solo de paso aquí en la tierra: mañana o pasado” (León-Portilla, 2006, p. 203). Si no es aquí en la tierra, en el tlaltícpac, ¿dónde está lo verdadero? “A dónde iremos, donde la muerte no existe? ¿Mas por esto viviré llorando? Que tu corazón se enderece: aquí nadie vivirá para siempre. Aun los príncipes a morir vinieron, hay incineramiento de gente. Que tu corazón se enderece: aquí nadie vivirá para siempre” (Martínez, 1984, p. 211). En la tierra solo se está de paso, esta vida es transitoria y no es para permanecer aquí, el estar del hombre en el mundo no es el fin, es solo un paso, el rumbo al que el corazón ha de apuntar trasciende este mundo.

\section{La verdad nahua}

COMO SE HA MOSTRADO HASTA ACÁ, lo verdadero para los nahuas es aquello que es firme, permanente, está fijo, tiene raíz, está bien cimentado. "La verdad, en náhuatl, neltiliztli, es término derivado del mismo radical que tla-nél-buatl: 'raíz', del que a su vez directamente se deriva: nelhuáyotl: 'cimiento, 'fundamento”" (León-Portilla, 1983, p. 122). Los humanos se vuelven conocedores de la realidad, conocen la verdad, neltiliztli, cuando han arraigado sus "disposiciones emocionales, imaginativas y físicas profunda y firmemente en el sagrado, téot ${ }^{\prime}$ ' (Maffie, 2008, p. 46). La filosofía occidental enuncia y responde a preguntas como ¿qué es la verdad?, ¿qué es lo real?, buscando así la adaequatio intellectus cum re. Los nahuas buscan una forma de vivir, orientada al conocimiento del 
camino correcto. Así, el término neltiliztli también significa 'bien arraigado, 'autorrevelación', 'autenticidad'. Lo arraigado, verdadero o el camino genuino se dice nelli obtli. Tlamatiliztli es 'conocer el camino'. La verdad no es alétheia, como en Occidente (Maffie, 2012, pp. 5-12), sino el estar arraigado a la realidad que permanece, no evanescente, caduca ni contingente, el téotl. Los nahuas entendieron la verdad como el deseo de saber cómo caminar verdaderamente sobre la superficie resbaladiza de la tierra para permanecer unido al téotl (Maffie, 2002a, p. 89).

El conocimiento se adquiere por medio de un yoltéotl, 'un corazón endiosado', y no por los sentidos. La comprensión del téotl es expresada en "flor y canto". La conciencia mística es el modo como el téotl florece en el corazón de una persona, se desenmascara y se revela. El téotl es invisible como la noche, intangible como el viento, yohualli-ehecatl: 'noche y viento'. Téotl es una fuerza sagrada, energía o poder. Es único, dinámico, vivificante, eternamente autogenerador y autorregenerador, es energía en movimiento siempre activa, actualizada y actualizante, siempre fluida, crea el cosmos y todo lo que sucede en el cosmos (Maffie, 2008, pp. 34-38). "El proceso incesante de téotl de generar y regenerar el universo es también uno de incesante autotransformación y retransformación. El universo es la autotransmutación de téotl, no su creación ex nibilo" (Maffie, 2002a, p. 77). Los humanos conocen al téotl a través del mismo téotl, en una experiencia mística, el téotl es conocido relacionándose con él. La naturaleza y téotl son idénticos, son la misma energía sagrada (Maffie, 2002b p. 7). La metafísica nahua sostiene que lo ilusorio y no ilusorio gozan del mismo estatus ontológico. Téotl es real y esencialmente devenir, realidad con devenir. Todo lo terrenal, con su impermanencia y evanescencia, es totalmente real (Maffie, 1999, p. 19).

¿Cuál es la fundamentación del ser? “'Acaso son de verdad los hombres? Porque si no, ya no es verdadero nuestro canto. ¿Qué está por ventura en pie? ¿Qué es lo que viene a salir bien?” (León-Portilla, 1983, p. 122). Es visible la asociación de lo verdadero con estar en pie. Lo verdadero, lo que se mantiene arraigado, es lo que permanece y el canto expresa esa relación con el fundamento, con una realidad no contingente. El hombre no es algo verdadero, es solo un sueño, algo que llega, pasa y se va. "Solo venimos a dormir, solo venimos a soñar, no es verdad, no es verdad que venimos a vivir sobre la tierra; cual cada primavera de la hierba así es nuestra hechura" (León-Portilla, 2006, p. 139). 
En otro texto Nezahualcóyotl plantea cierto pesimismo ante el sentido de contingencia del hombre, de ser menesteroso. “¿Es verdad que nos alegramos, que vivimos sobre la tierra? No es cierto que vivimos. ¿ Hemos venido a alegrarnos en la tierra? Todos así somos menesterosos. La amargura predice el destino aquí. Al lado de la gente" (Martínez, 1984, p. 198). Pareciera que el ser humano es necesitado, tiene el anhelo por lo verdadero, por lo que es firme para enraizar la existencia. El contemplar la contingencia de los semejantes genera pena y pesar. La vida en esta tierra es un sueño, la verdadera vida es habitar en la casa de Dios. "Mañana o pasado, como lo quiera el corazón de aquel por quien todo vive, nos hemos de ir a su casa, joh amigos, démonos gusto!" (Martínez, 1984, p. 199). Dios es el que cumple el anhelo del ser humano, es el que da firmeza y raíz a la existencia en este mundo sutil y evanescente.

Solo la divinidad puede ser el fundamento del mundo y del ser humano. “¿Eres tú verdadero (tienes raíz)? Solo quien todas las cosas domina, el Dador de la Vida. ¿Es esto verdad? ¿Acaso no lo es, como dicen? ¡Que nuestros corazones no tengan tormento!” (Martínez, 1984, p. 191). El verdadero por excelencia es Ipalnemoani, 'el dador de la vida,' 'aquel por el quien se vive. "Compuesto de ipal 'por él' o 'mediante él'; nemohua, 'se vive o todos viven' (forma impersonal de nemi: 'vivir'), y el sufijo participial -ni que da al compuesto ipal-nemohua-ni el significado de 'aquel-por-quien-se-vive”' (León-Portilla, 2006, p. 382). El verdadero es también el 'inventor de gente, de hombres', Teyocoyani, "compuesto de te-, 'a los otros, la gente', y yocoyani, participio de yocoya, 'inventar', 'forjar con el pensamiento”' (León-Portilla, 2006, p. 389). Dios es el que da fundamento, el que inventa, es la raíz de todo. Otro modo de referirse a la divinidad es 'el que es noche y viento,' 'el invisible e impalpable', Yohualli-ehécatl. "Siendo como la noche no puede percibirse y, al ser también como el viento, resulta impalpable” (LeónPortilla, 2006, p. 396). Dios es 'el intangible'. Los nahua también se refieren a la divinidad como "Totecuio in ilhuicahua in tlaltipacque in mictlane: 'Nuestro Señor, dueño del cielo, de la tierra y de la región de los muertos”' (León-Portilla, 2006, p. 164).

Dios es Tloque Nahuaque, 'el dueño del cerca y del junto, 'que está en el anillo o circuito.' Compuesto por dos adverbios: tloc y nábuac, tloc significa 'cerca', y, náhuac 'en el anillo de, en el circuito. "Lo que está en 'el anillo de agua' es el mundo; cemanábuac" (León-Portilla, 2006, p. 393). Clavijero traduce Tloque Nabuaque 
como 'Aquel que tiene todo en sí.' "Garibay, a su vez, poniendo el pensamiento náhuatl en términos más cercanos a nuestra mentalidad, traduce: 'el que está junto a todo, y junto al cual está todo”' (León-Portilla, 2006, p. 167).

Dios es nombrado también Moyocoyani, 'el que a sí mismo se inventa' (LeónPortilla, 2006, p. 385). Mendieta, en su Historia Eclesiástica Indiana, escribe que los nahua se referían a Dios como "Moyucoyatzin ayac oquiyocux, ayac oquipic, que quiere decir que nadie lo creó o formó, sino que él solo por su autoridad y su voluntad lo hace todo" (León-Portilla, 2006, p. 169). Moyocoya-tzin significa 'Señor que a sí mismo se piensa o se inventa'. Ayac oquiyocux significa 'nadie lo hizo o inventó a él', y por último ayac oquipic: 'nadie le dio ser o forma'. "Se busca su gloria, su fama en la tierra. Él es quien inventa las cosas, Él es quien se inventa a sí mismo: Dios. Por todas partes es también venerado. Se busca su gloria, su fama en la tierra" (Martínez, 1984, p. 189). Dios es el fundamento de todo y de sí mismo.

\section{Flor y canto}

LO ÚNICO QUE PUEDE SER VERDADERO SOBRE LA TIERRA es in xóchitl in cuicatl, 'la flor y el canto', que es la poesía. Esta es el enlace entre lo humano y lo divino, y permite expresar la verdad de las cosas (Hernández Díaz, 2013, pp. 32-36). La flor y el canto buscan lo verdadero. Gingerich, citando a Mijangos, traduce "nitlanelhuayotocac uel ynelhuayocan onacic", como 'descubrí la verdad de algo'. Literalmente, la oración dice: "Busqué sacar la raíz del asunto. Llegué completamente hasta el lugar donde estaban las raíces”. La poesía es el lenguaje que expresa lo verdadero, sin la enunciación de silogismos (Gingerich, 1987, p.103). La flor y el canto expresan lo verdadero no como concepto sino como reflexión de lo que permite una existencia ordenada a un fin. La búsqueda de una vida firme, con raíz. Los nahuas buscan conmover al receptor a una adhesión participativa, así que se busca que el mensaje sea sentido más que comprendido (Johansson, 2005, p. 523).

La flor y el canto permanecerán a pesar de la transitoriedad humana, pues otros seguirán cantando: "no acabarán mis flores, no acabarán mis cantos; yo los elevo: soy un cantor” (Martínez, 1984, p. 184). El lenguaje poético es una aproximación a la realidad, se presenta al ser como una presencia y no como 
proposiciones racionales. El lenguaje poético está asociado al ser, no se apropia de la realidad sino que está como parte de la realidad, está en el ser. La mejor manera de expresar la presencia del ser es con la poesía (Gingerich, 1987, pp. 100-103). "Como si fueran flores, los cantos son nuestro atavío, oh amigos: con ellos venimos a vivir en la tierra. Verdadero es nuestro canto, verdaderas nuestras flores, el hermoso canto" (Martínez, 1984, p. 182). No son proposiciones enunciativas racionales, sino descriptivas de una forma de vida para permanecer firme, enraizada. La poesía permanece de generación en generación, así es como se trasmitió la cultura. Tecayehuatzin respecto de la flor y el canto pregunta: “'Allá lo aprueba tal vez el Dador de la Vida? ¿Es esto quizá lo único verdadero en la tierra?” (León-Portilla, 1983, p. 128).

Si flor y canto son lo único verdadero, ¿cuál es su origen? "Sacerdotes, yo os pregunto: ¿De dónde provienen las flores que embriagan al hombre? ¿El canto que embriaga, el hermoso canto?” (León-Portilla, 2006, p. 144). La flor y el canto provienen de Dios. "Ahora sé feliz, ahora engalánate, tú, príncipe Nezahualcoyotl: toma para ti las flores de aquel por quien vivimos" (Martínez, 1984, p. 185). Si lo único que tiene raíz, fundamento, lo que es verdadero en el tlaltícpac es la flor y el canto, in xóchitl in cuicatl, y el único verdadero es Moyocoyani, 'el que a sí mismo se inventa', entonces flor y canto solo pueden venir de Dios. "Solo provienen de su casa, del interior del cielo, solo de allá vienen las variadas flores" (León-Portilla, 2006, p. 145).

El toltécatl, 'el hombre rostro sabio y corazón firme', es igualmente 'el que dialoga con su propio corazón', mo-yolnonotzani. El que busca lo firme y lo recto es el que puede comunicar lo verdadero con la flor y el canto. El artista, yoltéotl, 'corazón endiosado', se esfuerza y se angustia por introducir a la divinidad en las cosas, por eso se lo llama también "tlayolteubuiani, 'aquel que introduce el simbolismo de la divinidad en las cosas"” (León-Portilla, 2006, p. 270). Es el que con la flor y el canto expresa la verdad, el camino para echar raíces, para estar firmes. La poesía es un don de Dios. "Realidades preciosas haces llover, de ti proviene tu felicidad, ¡Dador de la Vida! Olorosas flores, flores preciosas, con ansia yo las deseaba, vana sabiduría tenía yo" (Martínez, 1984, p. 192). Lo verdadero en el tlaltícpac son la flor y el canto que en el artista son inspiradas por el Tloque Nahuaque: “Es un puro jade, un ancho plumaje tu corazón, tu palabra, ¡oh padre nuestro! ¡Tú compadeces al hombre, Tú lo 
ves con piedad! ... ¡Solo por un brevísimo instante está junto a ti y a tu lado!” (Martínez, 1984, p. 193).

\section{La modernidad}

La primacía de la razón comienza en Europa con Descartes (Dussel, 2008), con la separación entre res extensa y res cogitans, entre el cuerpo y la conciencia. El sujeto que conoce y representa el mundo lo hace a través de la razón, de manera que la representación que del mundo se puede hacer ha de ser racional. No hay certeza en la información que dan los sentidos, la razón es la garante de la fiabilidad de los conocimientos. Con el racionalismo moderno de Descartes, Kant y Hegel, el sujeto es el punto de partida de la realidad. Si en la Edad Media el centro era Dios, en la modernidad el centro es el sujeto: la realidad se estudia mediante la representación que el sujeto hace del mundo.

\subsection{DESCARTES: LA SUBJETIVIDAD DESCUBIERTA}

LA MODERNIDAD NACE CON LA CONSTITUCIÓN DEL SUJETO QUE CONOCE. En el Discurso del método, obra que mejor presenta "una visión de conjunto de su pensamiento científico y filosófico” (Basart Muñoz, 2004, p. 106), Descartes (2011) afirma: "yo pienso, luego soy" (p. 123). El sujeto es allí el referente de todo conocimiento, y el punto de partida para la filosofía es la subjetividad del individuo. A partir de la conciencia del sujeto se construye el horizonte conceptual cartesiano. En este horizonte, la razón es autónoma en el sujeto que piensa y en su ejercicio impone la duda que corroe el sujeto. La "duda afecta incluso las evidencias 'más claras', es posible que la mayoría de las opiniones tengan un origen incierto" (Cuautle \& Anakaren, 2011, p. 246). Pero a la vez, la duda da la posibilidad de conocer el mundo (Velázquez Delgado, 2005). El pensar las cosas de manera clara y distinta es el camino para conseguir la certeza de que se piensa, y del pensar se deduce la propia existencia.

El fundamento de todo conocimiento está, así, en el sujeto que dialoga consigo mismo, y esto "fundamenta la autonomía del procedimiento racional sobre la evidencia del cogito" (Daturi, 2011, p. 277). El sujeto conoce, duda de lo que conoce, si duda es porque piensa y si piensa es porque existe: pienso luego existo. 
Influenciado por San Agustín de Hipona, para Descartes el conocimiento es fraguado en la soledad del sujeto. En los Soliloquios del Obispo de Hipona (libro II, capítulo I), la razón dialoga con Agustín. “-¿Sabes que piensas? -Sí, eso lo sé. -Entonces sabes que, cuando menos, eso es verdad. -Cierto. -Luego sabes que existes, que vives y que piensas" (citado en Fernández et al., 2006, p. 405).

No solo la propia existencia se deduce de pensar, sino que la existencia de todo se deduce del pensamiento. Cuando las cosas se conciben de manera clara y distinta son verdaderas. Así, si se concibe de manera clara y distinta que Dios es un ser perfecto e infinito entonces se tiene la certeza de que Dios existe, y que es un ser perfecto e infinito. Y también se concibe entonces que lo que está en el sujeto proviene de Dios, de lo que se sigue que "nuestras ideas o nociones, cuando son claras y distintas, cosas reales y procedentes de Dios, no pueden por menos de ser también, en ese respecto, verdaderas" (Descartes, 2011, p. 127). Puesto que lo real y verdadero procede de un ser perfecto e infinito, el error es imperfección y, por tanto, no pude venir de Dios (Schöndorf, 1996, p. 114). El fundamento de la razón y la verdad es Dios.

En la tercera de sus Meditaciones metafísicas, Descartes dice: "reconozco que no sería posible que mi naturaleza fuese tal como es, es decir, que tuviese en mí la idea de un Dios, si Dios no existiese verdaderamente" (Descartes, 2011, p. 191). La fuente del conocimiento es, así, una razón encerrada en sí misma que acude a Dios como fundamento del conocimiento racional. Pero es importante notar que en este razonamiento no se produce una interacción personal con Dios. Dios es fuente de las ideas para el sujeto (Gomila Benejam, 1996, p. 54).

En las Meditaciones metafisicas, Descartes examina la idea de que exista un mundo creado por Dios, a partir de una deducción (Rojas, 2017, p. 314), "el solo hecho de que Dios, es decir, un ser soberanamente poderoso exista, se sigue que, si hay un mundo, debe haber sido creado por Él" (Descartes, 2011, p. 285). En este sentido la ciencia es un producto de la razón. Basta con que la razón realice una introspección para obtener ideas claras y distintas, sustentadas en que proceden de Dios, para tener la certeza de ser verdaderas. Es suficiente pensar que existe un Dios poderoso, perfecto e infinito para que exista Dios. La existencia del mundo se colige de la existencia de un Dios poderoso 
creador. De este modo, de la subjetividad del sujeto se conoce y se deduce la existencia de la realidad.

\subsection{KANT: LAS CONDICIONES DE LA SUBJETIVIDAD}

Si con Descartes se descubre la subjetividad como fuente de conocimiento, con Kant se plantean los límites del conocimiento. En el sujeto hay estructuras a priori en la mente, son innatas y permiten que se dé y se organice el conocimiento. "Espacio y tiempo valen como condiciones de la posibilidad de que nos sean dados objetos" (Kant, 1982, p. 86). Kant no analiza el objeto del conocimiento sino las condiciones en las que se da el conocimiento del objeto (Guerrero Pino, 2005, pp. 44-45).

Las formas del espacio y el tiempo condicionan el conocimiento: todo lo que se conoce, se conoce al presentarse en un momento y en un lugar, por lo que no se conocen las cosas en sí mismas tal y como son, sino con los límites de la razón, con los límites de las estructuras a priori. Kant le da "el nombre de noúmenos a las cosas en sí mismas” (Kant, 1982, p. 151). El noúmeno, la cosa en sí, no es cognoscible por los sentidos (Neumann Soto, 2016, p. 15). El concepto noúmeno es un concepto ligado a las limitaciones de la sensibilidad al no conocer las cosas en sí mismas (Osorio, 1999), pues no se conocen las cosas en sí mismas sino como meras representaciones (Benzi Zenteno \& Soto Herrera, 2006).

El conocimiento que se tiene del mundo no es tal como es el mundo, sino como puede conocerlo el sujeto. El mundo como tal no se conoce, pero la razón puede examinar cómo el mundo puede ser conocido. Kant plantea el problema del conocimiento y el papel que en su construcción juega la relación objeto-sujeto (García, 2006, p. 116), y se pregunta por las condiciones de posibilidad para que se dé el conocimiento. No se sabe cómo es el mundo, la realidad: lo que se indaga es cómo el sujeto se representa la realidad.

Si con Descartes el sujeto es el fundamento del conocimiento, con Kant la posibilidad del conocimiento está condicionada a no conocer la cosa en sí, sino a la representación que la razón por sus características permite formarse. Así, 
mientras que con Descartes se descubre la subjetividad, con Kant se descubre la constitución de la subjetividad.

\subsection{HEGEL: EL SUJETO ABSOLUTO}

Con Hegel la Subjetividad y la REALIdad se constituyen en una unidad. El conocimiento se fundamenta a sí mismo, en la medida en que es un conocer que conoce al objeto y al conocer al objeto se conoce a sí mismo. "Lo que es racional es real; y lo que es real es racional" (Hegel, 1968, p. 34).

En la Fenomenología del espiritu, Hegel (2003) busca que la filosofía llegue al saber real: "Contribuir a que la filosofía se aproxime a la forma de la ciencia - a la meta en que pueda dejar de llamarse amor por el saber- para llegar a ser saber real: he ahí lo que yo me propongo" (p. 9). Un saber real en tanto es saber de lo que es (Rendón, 2008). Este propósito exige que el conocimiento sea universal y no dependa de la singularidad, contingencia y motivaciones del sujeto.

El conocimiento de la ciencia es, entonces, un conocimiento universal, necesario, absoluto; no particular, contingente ni singular. El conocimiento sensible se presenta como el más inmediato y verdadero, teniendo al objeto en su plenitud como otro. Esta certeza sensible, aunque parezca inmediata, es algo mediado: "yo tengo la certeza por medio de un otro, que es precisamente la cosa; y esta, a su vez, es en la certeza por medio de un otro, que es precisamente el yo" (Hegel, 2003, p. 64). El objeto sensible se presenta ante el sujeto como algo diferente de él, como otro, así se da la relación sujeto-objeto.

Pero si bien la conciencia inicia con la certeza sensible, ha de culminar con el saber absoluto (López, 2015, p. 61). Para Hegel (2003) la conciencia se da cuando se conoce la cosa, el objeto, mientras que "la autoconciencia es la reflexión, que desde el ser del mundo sensible y percibido, es esencialmente el retorno desde el ser otro" (p. 158). En otras palabras, el sujeto conoce y cuando se da cuenta de que conoce se presenta la autoconciencia. En ese momento la conciencia se conoce a sí misma como objeto. "La autoconciencia convierte a la conciencia en su objeto de conocer, convierte su ser para sí en cosa, se da la unidad del yo y del ser" (p. 206). La manera como la razón se conoce es presentándose a sí misma como objeto. El sujeto solo puede conocerse como objeto de conocimiento. El 
sujeto se vuelve objeto, de manera que hay una coincidencia de sujeto y objeto, de la conciencia y el mundo (Assalone, 2015, p. 65). El sujeto se conoce a sí mismo al ser objeto de conocimiento de sí mismo.

La conciencia conoce la realidad y cuando se conoce a sí misma, como autoconciencia, se conoce como realidad objetiva, es decir, la razón se conoce a sí misma como realidad. La autoconciencia es el saber que sabe de sí, se ve a sí misma como otro ser, este otro ser es ella misma. De este modo, el saber de la conciencia se fundamenta en esta misma, es un saber en el que el objeto y sujeto configuran una identidad en su misma diferencia (Díaz, 2009, p. 33).

En la medida en que la conciencia es el saber de la esencia y la realidad de las cosas, y el espíritu es la autoconciencia que se capta a sí misma -el saber de la conciencia de sí misma-, la realidad es para la conciencia su voluntad representada. "La esencia [es] lo que se mantiene [...] es el ser en sí y para sí" (García Aguilar, 2013, p. 4). Para Hegel (2003), el saber de la autoconciencia es el saber de las esencias, de la sustancia misma: "La esencia y la realidad son el saber de la conciencia acerca de sí misma” (p. 344), es saber cómo sabe la propia conciencia de sí misma (Rojas Hernández, 2011, p. 242). La esencia define la realidad por lo que la conciencia, al conocer la esencia, conoce de la realidad. Realidad que en la autoconciencia es ella misma, luego entonces la representación de la realidad es la representación de la misma autoconciencia. Y dado que la conciencia y la autoconciencia son el espíritu, entonces la realidad es el mismo espíritu; el mundo es para la conciencia la voluntad del espíritu.

En la historia, en el devenir, es donde el espíritu se mediatiza a sí mismo, se capta como otro y se conoce a sí mismo. "La autoconciencia es un saber que es al mismo tiempo devenir: reflexividad" (Cuevas, 2016, p. 37). El espíritu se sabe a sí mismo como espíritu, en el devenir, en la historia. El saber real se da en la historia, en ella se "forman el recuerdo y el calvario del espíritu absoluto, la realidad, la verdad y la certeza de su trono, sin el cual el espíritu absoluto sería la soledad sin vida" (Hegel, 2003, p. 473).

Con Hegel el sujeto se sustenta a sí mismo y el mismo sujeto es el que sustenta la realidad. La historia es el escenario en el que el espíritu se conoce a sí mismo. Se absolutiza al sujeto como fuente, origen de la realidad, pues fuera del sujeto no hay realidad. Es en el devenir en el que el espíritu absoluto se va conociendo a sí mismo. Si el espíritu absoluto sustenta el objeto, lo que 
importa no es el objeto sino el sujeto, y el sujeto, como espíritu absoluto, puede sustentar el objeto. En la Edad Media, Dios era el centro de la reflexión, era el ser que sustentaba el mundo, el creador del mundo. Con Hegel, el sujeto como espíritu absoluto es el centro de la reflexión, sustenta el mundo, ocupa el lugar de Dios.

\section{Conclusión}

La modernidad nace con Descartes, pues es allí donde el sujeto es el referente de todo conocimiento, y la subjetividad del individuo es el punto de partida para la filosofía. El conocer es un aspecto que tiene que ver con lo racional, con una mera función intelectual, y en su fundamentación se desconfía de los sentidos, de la sensibilidad. En ese sentido, conocer está relacionado con lo meramente conceptual.

Para los nahuas, en cambio, los humanos se vuelven conocedores de la realidad, conocen la verdad, neltiliztli, cuando han arraigado sus disposiciones emocionales, imaginativas y físicas profunda y firmemente en el sagrado, Téotl, que es el fundamento de todo. La filosofía occidental busca la adaequatio intellectus cum re. Los nahuas buscan una forma de vivir orientada al camino correcto, nelli obtli. Tlamatiliztli: 'en conocer el camino'. La verdad está relacionada con cómo vivir en este mundo con una ética, y no a las cuestiones metafísicas de la filosofía occidental.

Mientras en Descartes el conocimiento es fraguado en la soledad, el sujeto aísla la parte racional de la emocional, la duda cuestiona sus conocimientos y le da la certeza de la propia existencia al tener ideas claras y distintas, en la tradición náhuatl cuando se duda el corazón está dividido, ome yolloa. No se trata de una cuestión conceptual, pues la duda está referida también a cuestiones emocionales y existenciales, es 'no saber a dónde dirijo mi andar'.

En Descartes las ideas que se conciben de manera clara y distinta son verdaderas. Si se concibe de manera clara y distinta que Dios es un ser perfecto e infinito entonces se tiene la certeza de que Dios existe, que es un ser perfecto e infinito y lo que está en el sujeto proviene de Dios, el error es un imperfección y Dios siendo perfecto no puede permitir tal imperfección. En la cultura nahua no es por lo claro y distinto de las ideas como se aproxima a la verdad. 'Flor y canto' in xóchitl in cuicatl, es la manera como los tlamatinime expresan y se aproximan 
a la verdad. El conocimiento se adquiere por medio de un yoltéotl, 'un corazón endiosado'. La conciencia mística es el modo como el Téotl florece en el corazón de una persona, se desenmascara y se revela. El Téotl es invisible como la noche, intangible como el viento, Yohualli-ehecatl. La flor y el canto son el enlace entre lo humano y lo divino, expresan la verdad de las cosas, no como concepto sino como reflexión de lo que permite una existencia ordenada a un fin, la búsqueda de una vida firme, con raíz. El lenguaje poético es una aproximación a la realidad, se presenta al ser como una presencia y no como proposiciones racionales sobre el ser. El lenguaje poético está asociado al ser, no como apropiación sino como parte de la realidad. Y por ello el artista, yoltéotl, es el tlayolteuhuiani, aquel que introduce el simbolismo de la divinidad en las cosas. Es el que recibe del Dador de la vida la flor y el canto.

En la filosofía europea palabras como reflexionar y pensar son funciones meramente racionales, procesos solamente conceptuales. En la tradición mesoamericana las palabras reflexionar y pensar están referidas a procesos racionales y emocionales, están imbricados procesos experienciales del sujeto, lo que es claro en el término ninoyolnonotza, que significa reflexionar, 'dialogar con el corazón', y en la expresión mo-yolnonotzani, 'dialoga con su propio corazón'. El verbo náhuatl tlalnamiqui significa 'pensar, encontrar, recordar algo', no es un proceso en el que se entrelazan solamente conceptos: una premisa con otra. Se hace referencia a traer al presente lo experimentado, lo vivido, situarse en un contexto de tiempo. En ello también se diferencia el pensamiento nahua del de Kant, para quien las categorías de espacio y tiempo son condiciones de posibilidad para descubrir cómo es que la razón conoce. En la tradición tolteca, en cambio, no son condiciones de posibilidad, sino que la experiencia, lo vivido, el tiempo y el espacio forman parte del proceso cognitivo.

En la modernidad con Hegel, el sujeto se absolutiza, el sujeto se sustenta a sí mismo y el mismo sujeto es el que sustenta la realidad. La historia es el escenario en el que el espíritu se conoce a sí mismo. En la cultura nahua, es Dios el que a sí mismo se inventa: Moyocoyani, 'el sustento de todo'.

La modernidad ensalzó la razón, y consideró el conocimiento científico como el saber por excelencia. Un saber centrado en el sujeto, un saber al que solo le importa la autosatisfacción de una lógica lineal, que empobrece y da una representación parcial del mundo y del ser humano. La razón ha procreado una 
lógica instrumental que destruye el mundo, la naturaleza y al ser humano. La tradición de las culturas ancestrales como la nahua no sostiene esa racionalidad instrumental, sino una representación y actuar del hombre en el mundo que integra lo conceptual, la sensibilidad y la memoria para fundamentar la vida: que el hombre sea de un rostro sabio y corazón firme, que dialogue con su propio corazón, que busque lo recto lo verdadero, lo que tiene raíz. En ese sentido, reflexionar no es una introspección en el ámbito meramente cognitivo, es fundir la argumentación intelectualmente configurada en el crisol de la sensibilidad.

Además, hay un estrecho vínculo en el náhuatl entre pensar, sentir y recordar. La escisión res extensa y res cogitas, cuerpo y alma, está ausente en el pensamiento nahua. En los procesos cognitivos de la filosofía nahua participan también los órganos del cuerpo como el corazón que se asocia a las facultades cognoscitivas, volitivas y creativas.

\section{Referencias}

Assalone, E. (2015). Hegel normativista. La prioridad de la práctica, la autoconciencia como logro social y como sujeto de estados normativos, en el cap. IV de la Fenomenología del espiritu. Ideas y Valores, 64(158), 61-84.

Baena, R. A. (2018). Pensamiento en imágenes. La configuración del sacrificio en los códices del grupo Borgia. Tesis de doctorado en Antropología Social, Centro de Investigaciones y Estudios Superiores, Universidad Nacional Autónoma de México.

Barrera-Ramirez, C. F., \& Guerrero-Orduna, E. A. (1999). El corazón y la sangre en la cosmovisión Mexica. Gaceta Médica de México, 135(6), 641-651.

Basart Muñoz,J. (2004). Conocimiento y método en Descartes, Pascal y Leibniz. CIENCIA ergo-sum, Revista Cientifica Multidisciplinaria de Prospectiva, 11(1), 105-111.

Benzi Zenteno, I., \& Soto Herrera, C. (2006). Teoría kantiana de la actividad mental: Algunos problemas desde la ciencia cognitiva. Revista de filosofía, 62, 41-58.

Bernal, I. (1984). Tenochtitlán en una Isla. México D.F.: Fondo de Cultura Económica.

Cortés, H. (1985). Cartas de relación. México D.F.: Porrúa. 
Cuautle, R., \& Anakaren, M. (2011). Constitución epistemológica del cogito cartesiano. Andamios. Revista de Investigación Social, 8(16), 241-260.

Cuevas, L. (2016). Spinoza, Hegel, Deleuze y el problema de la inmanencia. Guillermo de Ockham: Revista cientifica, 14(2), 33-41.

Daturi, D. (2011). El sentido de la obra de Descartes a la luz de la tradición y su valor prospectivo. CIENCIA ergo-sum, Revista Cientifica Multidisciplinaria de Prospectiva, 18(3), 275-282.

De-Regil, L. M., \& Casanueva, E. (2008). Racionalidad científica, causalidad y metaanálisis de ensayos clínicos. Salud Publica de México, 50(6), 523-529.

Descartes, R. (2011). Descartes. Madrid: Gredos.

Díaz, J. A. (2009). Lo absoluto del saber absoluto. Eidos: Revista de Filosofía de la Universidad del Norte, 11, 10-34.

Dussel, E. (2008). Meditaciones anti-cartesianas: sobre el origen del anti-discurso filosófico de la modernidad. Tabula Rasa, 9, 153-197.

Esquivel Estrada, N. H. (2017). Dios, en el pensamiento de Descartes. La Colmena, 30, 123-132.

Fernández, S., O., Cárdenas, A., Pedro, P., \& Fernando, M. (2006). René Descartes, un nuevo método y una nueva ciencia. Scientia Et Technica, XII(32), 401-406.

Florescano, E. (1963). Tula-Teotihuacán, Quetzalcóatl y la Toltecayótl. Historia Mexicana, 13(2), 193-234.

García Aguilar, R. (2013). Sujeto y verdad en el Prólogo de la Fenomenología del espiritu, de Guillermo Federico Hegel. Revista Espiga, 26, 1-10.

García, R. (2006). Epistemología y Teoría del Conocimiento. Salud Colectiva, 2(2), 113-122.

Garibay, A. (1961). Llave del nábuatl. México: Porrúa.

Gingerich, W. (1987). Heidegger and the Aztecs: The poetics of knowing in pre-Hispanic Nahuatl poetry. En B. Swan \& A. Krupat (Eds.), Recovering the Word: Essays on Native American Literature. Berkeley: University of California Press. E-boook.

Giraldo Garcés, G. A. (2007). Racionalidad y ética en las organizaciones. Cuadernos de Administración, 38, 53-62.

Gomila Benejam, A. (1996). La teoría de las ideas de Descartes. Teorema: Revista internacional de filosofia, 16(1), 47-69. 
Graña-Behrens, D. (2012). Itz'aat and Tlamatini. The "Wise Man" as Keeper of Maya and Nahua Collective Memory. En: Megged and Stephanie Wood (Ed.), Mesoamerican Memory: Enduring Systems of Remembrance (pp. 1532). University of Oklahoma Press.

Guerrero Pino, G. (2005). Teoría kantiana del espacio, geometría y experiencia. Praxis filosófica, 20, 31-68.

Hegel, G. W. F. (1968). Filosofía del derecho. Buenos Aires: Editorial Claridad. Hegel, G. W. F. (2003). Fenomenología del espiritu. México: Fondo de Cultura Económica.

Hernández, Díaz, M. (2013). El concepto de hombre y el ser absoluto en las culturas Maya, Nábuatl y Quechua-Aymara. México: Universidad Nacional Autónoma de México.

Jansen, M. (1997). Símbolos de poder en el México antiguo. Anales del Museo de América, 5, 73-102.

Johansson, P. (2004). ¿Ie ixiloiocan, yn imiyaoayocan oacico tlatolli? ¿Ya llegó a Jilote, ya llegó a mazorca el discurso? Consideraciones epistemológicas indígenas en el libro IV de la Historia General. Estudios de cultura Nábuatl, 35, 207-224.

Johansson, P. (2012). La muerte en la cosmovisión náhuatl prehispánica. Consideraciones heurísticas y epistemológicas. Estudios de cultura nábuatl, 43, 47-93.

Kant, E. (1982). Critica de la razón pura. México: Porrúa.

Lee, J. (2017). The Europeanization of Prehispanic Tradition: Bernardino de Sahagún's transformation of Aztec priests (tlamacazque) into classical wise men (tlamatinime). Colonial Latin American Review, 26(3), 291-312.

León-Portilla, M. (1980). Toltecáyotl. Aspectos de la cultura nábuatl. México D.F: Fondo de Cultura Económica.

León-Portilla, M. (1983). Los antiguos mexicanos a través de sus crónicas y cantares. México D.F.: Cultura SEP Fondo de Cultura Económica.

León-Portilla, M. (2004). Significados del corazón en el México prehispánico. Archivos de cardiología de México, 74(2), 99-103.

León-Portilla, M. (2006). La filosofía náhuatl estudiada en sus fuentes. México D.F.: UNAM. Instituto de Historia: Seminario de Cultura Nahua. 
López Austin, A. (1991). Cuerpos y rostros. Anales de Antropología, 28, $317-$ 335.

López Austin, A. (2003). Difrasismos, cosmovisión e iconografía. Revista española de antropología americana, 1, 143-160.

López Austin, A. (2004). Cuerpo humano e ideología. Vol II. México: UNAM.

López, D. M. (2015). La construcción lógica de la Fenomenología del espíritu de Hegel. Tópicos, 30, 40-63.

Maffie, J. (1999). The region of the fleeting moment. Paideusis, Journal for Interdisciplinary and Cross-Cultural Studies, 2, 15-23.

Maffie, J. (2002a). Why Care About Nezahualcoyotl? Veritism and Nahua Philosophy. Philosophy of the Social Sciences, 32(1), 71-91.

Maffie, J. (2002b). "We Eat of the Earth Then the Earth Eats Us": Pre-hispanic Nahua Thought. Ludus Vitalis, X(17), 5-19.

Maffie, J. (2008). Watching the Heavens with a 'Rooted Heart': The Mystical Basis of Aztec Astronomy. Culture and Cosmos, 12(1), 31-64.

Maffie, J. (2012). In Huebue Tlamanitiliztli and la Verdad: Nahua and European Philosophies in Fray Bernardino de Sahagún's Colloquios y doctrina cristiana. Inter-American Journal of Philosophy, 3(1), 1-33.

Manrique, J. A. (1960). Introducir a la divinidad en las cosas: finalidad del arte náhuatl. Estudios de Cultura Nábualt, 2, 197-207.

Martínez, J. L. (1984). Nezahualcóyotl vida y obra. México D.F.: Fondo de Cultura Económica.

Mauss, M. \& Hubert, H. (2010). Elsacrificio. Magia, mito y razón. Buenos Aires: Las Cuarenta.

Máynez, P. (2009). Los difrasismos en la obra inédita de Ángel María Garibay. Estudios de cultura Nábuatl, 40, 235-251.

Mikulska Dabrowska, K. (2007). La comida de los dioses. Los signos de manos y pies en representaciones gráficas de los nahuas y su significado. Itinerarios: revista de estudios lingüisticos, literarios, históricos y antropológicos, 6, 11-37.

Mikulska Dąbrowska, K. (2010). "Secret Language" in Oral and Graphic Form: Religious-Magic Discourse in Aztec Speeches and Manuscripts. Oral Tradition, 25(2), 325-363.

Molina, A. de. (1571). Vocabulario en lengua castellana y mexicana, parte 2. Antonio de Spinosa. 
Montes de Oca, M. (1997). Los disfrasismos en el náhuatl, un problema de traducción o de conceptualización. Amerindia, 22, 31-44.

Montes de Oca, M. (2000). Los difrasismos en el náhuatl del siglo XVI. Tesis de doctorado en Estudios Mesoamericanos, Facultad de Filosofía y Letras, Universidad Nacional Autónoma de México.

Montes de Oca, M. (2016). Los difrasismos y la construcción de la identidad de la nobleza indígena. En P. Lesbre \& K. Mikulska (Eds.), Identidad en palabras. Nobleza indígena novohispana (pp. 249-266). México: UNAM, Instituto de Estudios Ibéricos e Iberoamericanos de la Universidad de Varsovia y Universidad Toulouse.

Montiel, J. (2019). Aztec Metaphysics-Two Interpretations of an Evanescent World. Genealogy, 3, 59. doi: 10.3390/genealogy3040059

Neumann Soto, H. (2016). Casos de pérdida del sentido. La tabla de la nada en Kant. Ideas y Valores, 65(162), 9-34.

Ocaña-Servína, H. L., Tlatoa-Ramíreza, H. M., Jaimes-García, J., Karam-Calderón, M. A., García-Rillo, A., Arceo-Guzman, M. E., \& Pimentel-Ramírez, M. L. (2016). Los sacrificios humanos entre los aztecas. Un contexto de poder, mito y religión. Medicina e Investigación, 4(1), 42-45.

Osorio, F. (1999). Posibilidad de una teoría del conocimiento anoumenal en Kant. Cinta de Moebio, 5, 19-36.

Payás, G. (2006). El historiador y el traductor. El complejo Garibay/León-Portilla. Fractal, 42, 51-86.

Rendón, C. E. (2008). El devenir de Hegel hacia la Fenomenología del espíritu. Ideas y Valores, 57(137), 41-61.

Rojas Hernández, M. (2011). La razón autorreflexiva como principio de la filosofía de Hegel. Andamios, Revista de Investigación Social, 8(15), 239-271.

Rojas, S. (2017). La cosa que piensa: una lectura de las Meditaciones metafísicas de Descartes. Revista de filosofía, 73, 299-316.

Rubio Fernández, B. (2008). México-Tenochtitlán. Urbanismo de la capital azteca. Estrat Critic: Revista d'Arqueologia, 2, 55-60.

Sahagún, B. (1999). Historia General de las Cosas de Nueva España. México: Porrúa.

Schöndorf, H. (1996). Papel de Dios en el pensamiento de Descartes. Universitas Philosophica, 27, 107-130. 
Sejourné, L. (1984). Pensamiento y religión en el México antiguo. México: Fondo de Cultura Económica.

Sodi, D. (1962). Consideraciones sobre el origen de la toltecáyotl. Estudios de cultura Nábuatl, 3, 55-74.

Velázquez Delgado, J. (2005). La sombra de Descartes, el genio maligno y racionalidad moderna. La lámpara de Diógenes, 6(10), 161-168.

Viesca Treviño, C., Aranda Cruzalta, A., \& Ramos de Viesca, M. (2005). El corazón y sus enfermedades en la cultura náhuatl prehispánica. Estudios de cultura Nábuatl, 36, 225-244.

Wright Carr, D. C. (2011). La tinta negra, la pintura de colores: Los difrasismos metafóricos translingüísticos y sus implicaciones para la interpretación de los manuscritos centromexicanos de tradición indígena. Estudios de cultura nábuatl, 42, 285-298. 